\title{
Late Intrauterine Death
}

National Cancer Institute

\section{Source}

National Cancer Institute. Late Intrauterine Death. NCI Thesaurus. Code C124643.

A death of the fetus occurring inside the uterus. 